To cite this Article: Rantanen,T. ; Lehto, P. ; Vuorinen, P. \& Coco, K. (2017) Attitudes towards care robots among Finnish home care personnel - a comparison of two approaches. Scandinavian Journal of Caring Sciences, 1-11. First published: 22 August 2017.

DOI: $10.1111 /$ scs.12508

URL: http://onlinelibrary.wiley.com/doi/10.1111/scs.12508/epdf 


\title{
Attitudes towards care robots among Finnish home care personnel - a comparison of two approaches
}

\begin{abstract}
Study's rationale: The significance of care robotics has been highlighted in recent years. Aims and objective: The article examines the adoption of care robots in home care settings, and in particular Finnish home care personnel's attitudes towards robots. The study compares the importance of the Negative Attitudes towards Robots Scale advanced by Nomura and specific positive attitudes related to the usefulness of care robots for different tasks in the home care.

Methodological design: A cross sectional study conducted by questionnaire. The research data were gathered from a survey of Finnish home care personnel $(n=200)$.

Research methods: Exploratory factor analysis, Pearson's correlation coefficient and linear regression analysis.

Measures: The Negative Attitudes towards Robots Scale (NARS), by Nomura, with a specific behavioural intention scale based on Ajzen's theory of planned behaviour, and a measure of positive attitudes towards the usefulness of care robots for different tasks in home care and the promotion of independent living of older persons.

Results: The study shows that NARS helps to explain psychological resistance related to the introduction of care robots, although the scale is susceptible to cultural differences. Care personnel's behavioural intentions related to the introduction of robot applications are influenced also by the perception of the usefulness of care robots.

Study limitations: The study is based only on a Finnish sample, and the response rate of the study was relatively small $(18.2 \%)$, which limits the generalizability of the results.

Conclusions: The study shows that the examination of home care personnel's attitudes toward robots is not justified to focus only on one aspect, but a better explanation is achieved by combining the perspectives of societal attitudes, attitudes related to psychological reactions and the practical care and promotion of the independent living of older people.
\end{abstract}

Keywords: home care, attitude, elderly, health care personnel, survey, care robot

\section{Introduction}

The advance of robotics has been rapid over the last decade and the importance of care robots has been highlighted due to an aging of the population and the increased need for care. Robots have been developed with different functionalities, such as lifting robots, exoskeletons, assistive robots, companion robots, talking robots, emotional communication robots, and service robots which can provide physical, social and medical assistance to older people at home [1]. The capabilities of current care robots are quite limited, although studies have reported promising applications of assistive robots for the social and daily health care of older people [2]. In Finland home help and home nursing are available when older people require help in the home due to a weakened functional capacity or illness. In many Finnish municipalities these are combined as a provision of home care, which is supplemented by support services. The aim is to assist the older person's activities and safety whilst 
living at home. However, home nursing requires nursing and rehabilitation services which are prescribed by a doctor [3]. These services include services like wound care, medication, home visit made by a nurse, a physiotherapist, a qualified social worker or an occupational therapist. During the visit the clients receive physical training and information about assistive devices and adaptation of housing.

The introduction of robots will change care in many ways, and according to previous studies, the attitudes of care personnel play a key role when adopting new technology in health care $[4,5,6]$. Negative attitudes towards robots can slow down their introduction, but positive attitudes may accelerate the development. This study focuses on care personnel attitudes towards robots, and highlights their importance in the introduction of care robots.

\section{Previous studies on attitudes towards robots}

Attitude has been traditionally understood as a very persistent personal trait or behavioural tendency, but the concept is multidimensional and can be defined in different ways. On a general level, attitude can be understood as a value judgment of a given target [7]. However, the target of the attitude and the nature of the valuation can vary. Attitudes towards care robots and robots have been studied from different perspectives.

Firstly, some surveys have studied societal attitudes and conceptions related to the societal significance or negative social impacts of robots, both today and in the future. For instance, the European Commission's Special Eurobarometer 382 [8] mapped public attitudes towards robots and included questions related to general and more specific attitudes towards robots, the usefulness of robots in different areas of application, as well as the acceptance of robots in various tasks in the future. According to the survey, respondents believed in the usefulness of robots in space exploration, manufacturing, as well as in military and security use, but respondents felt that in the care of children, older people and people with disabilities, the use of robots should be banned. Up to $86 \%$ of respondents would feel 'uncomfortable' about having their children or older parents cared for by a robot.

Secondly, some studies have examined attitudes to robots together with their links to various psychological phenomena such as thoughts and feelings [9], emotional reactions [10], or without an exact conceptual distinction between attitudes and perceptions or psychological reactions [11]. Kou et al. examined interactions with the Charles robot using an attitude scale focused on six perceived features of robots (face, eyes, facial expression, voice clarity, the robot's instructions, and its overall 
performance). In the study they found differences between age groups, and also a significant gender effect, with males having a more positive attitude towards robots in healthcare than females [9]. Scopelliti et al. studied attitudes towards new technology, emotional reactions to domestic robots, and the preferred characteristics and interaction modalities of robots, and found different representations of robots ranging from the idea of a cold agent, to an image of a 'member of the family' that people could interact with in a peer-to-peer relationship [10].

Nomura's Negative Attitudes towards Robots Scale (NARS) [12] combines perspectives on societal attitudes and psychological reactions, and is targeted at human-robot interaction in specific situations, the social impacts of robots, and human-robot interaction and related emotions. According to Nomura's findings, attitudes towards robots [13] and anxiety related to robots [14] affect the communicative behaviour which takes place in human-robot interaction. Nomura et al. have also reported that attitudes towards robots are associated with people's assumptions about robots, such as their types and tasks [12].

Thirdly, some studies have focused on various tasks for care robots in health care or the promotion of independent living in older people [15, 16, 17, 18, 19]. For example, Broadbent at al. found people to believe health care robots may be useful for lifting heavy things [17], and Alaiad and Zhou questioned both healthcare personnel and older people as to what they felt were the most preferable tasks and applications for health care robots, and found that measuring vital signs on a regular basis and recording or submitting them to the doctor were felt to be the most important tasks for health care robots [15]. However, Mast at al., have shown that older people rated emergency assistance as the most important task of care robots, with informal caregivers rating items related to reminding functions and emergencies most highly [19]. (Cf. Table 1.)

Table 1: Attitudes towards robots in previous studies.

\begin{tabular}{lll}
\hline Perspective & What means? & Authors/Studies \\
\hline Societal attitudes & $\begin{array}{l}\text { Attitudes and conceptions related to the social } \\
\text { significance or negative social impacts of robots } \\
\text { today and in the future. For instance, the perceived } \\
\text { usefulness of robots in different areas of society, or } \\
\text { the worry that that robots would be a bad influence } \\
\text { on children. }\end{array}$ & $\begin{array}{l}\text { Eurobarometer 382 [8], Sub-scale 2 in } \\
\text { Nomura et al. NARS [12] }\end{array}$ \\
& $\begin{array}{l}\text { Attitudes related to immediate interactions with } \\
\text { robots. Attitudes are studied together with emotional et al. [11], sub-scales 1 and 3 in } \\
\text { reactions to robots, and the perceptions of robots. }\end{array}$ & $\begin{array}{l}\text { Nomura's et al. NARS [12] } \\
\text { Psychological } \\
\text { reactions }\end{array}$ \\
$\begin{array}{lll}\text { Practical care and the } \\
\text { promotion of } \\
\text { independent living }\end{array}$ & $\begin{array}{l}\text { The perceived usefulness of care robots for different } \\
\text { tasks in home health care and the promotion of } \\
\text { independent living in older people }\end{array}$ & $\begin{array}{l}\text { Alaiad \& Zhou [15], Broadbent [17], } \\
\text { Mast [19] }\end{array}$ \\
\hline
\end{tabular}


The research debate on attitudes towards robots involves various cross-cultural viewpoints. Nomura's original NARS is Japanese, and Syrdal et al. have suggested that while the scale may also be useful in examining English-speaking samples, it may be susceptible to cultural differences [20]. Furthermore, previous studies have also found some cultural differences in attitudes towards robots between Japanese and Western people [21, 22]. For example, in Western countries, negative attitudes and fears are more dependent on age than in Japan, and are more significant in 20 year olds than older age groups [22]. Moreover, the European Commission's Special Eurobarometer 382 found some national differences in public attitudes towards robots [8]. For example, in 24 member states of the EU, a majority think that the use of robots should be banned in the care of children, elderly people and people with disabilities. Public opinion was most emphatic in Cyprus (85\%) and Luxembourg (78\%), and only Portugal (35\%), Bulgaria (40\%) and Malta (49\%) were exceptions to this viewpoint.

\section{Ajzen's theory of planned behaviour and the concept of behavioural intention}

The determinants that affect the adoption of care robots can be analysed using the perspectives of a wide variety of theoretical models [15]. Previous studies [4, 5, 6] have shown Ajzen's theory of planned behaviour $[23,24]$ to be a useful approach for explaining the adoption of new technology in health care.

In the theory of planned behaviour, the concept of behavioural intention refers to the motivational factors that influence a behaviour, and give indications of how hard people are willing to try and how much effort they are likely to exert in order to perform the behaviour [23]. Typically, behavioural intention can find expression in behaviour only if the behaviour in question is under volitional control [23]. However, Rawstorne et al. [6] have argued that the theory of planned behaviour can also be applied to cases where the use of technology is mandatory.

According to the theory of planned behaviour, behavioural intention and behaviour are affected by attitudes and cognitions related to behaviour. In addition, Ajzen and Fishbein have argued that in specific situations, specific attitudes explain and predict behaviour much better than general attitudes $[25]$.

\section{Aim and objective}

This study examines care personnel's attitudes towards robots and in particular, the effect of attitudes on behavioural intentions related to the introduction of care robots. The study compares the importance of the Negative Attitudes towards Robots Scale advanced by Nomura and specific 
positive attitudes towards the usefulness of care robots for different tasks in home care and in the promotion of independent living of older people. Due to the multi-dimensional nature of Nomura's scale, the analysis combines perspectives of societal attitudes, psychological reactions related to human-robot interaction, as well as care and supporting of older people.

The study has been carried out in the context of a Finnish home care. In Finland the aim of Home Care Services is to support older people in coping at home for as long as possible and to secure older people's safe, active living at home [26]. According Turjamaa et al. [27], home care workers reported that clients mostly needed help with the administration of drugs, pharmacy services, and managing daily living activities. In addition the clients needed help coping with diseases or conditions like dementia [27].

\section{Questions and hypotheses}

The study asks whether Nomura's NARS is useful in studying Finnish home care personnel's attitudes and psychological resistance related to the introduction of care robots. In addition, the study compares the importance of the negative attitudes towards robots (NARS) and specific positive attitudes related to the usefulness of care robots for different tasks in the home care and the promotion of the independent living of older people. The following hypotheses will be tested:

H1 Care personnel's negative attitudes towards robots (NARS) have a negative effect on behavioural intentions related to the introduction of care robots.

H2 Care personnel's context-related attitudes towards the usefulness of care robots for different tasks in home care and the promotion of the independent living of older people have a positive effect on behavioural intentions related to the introduction of care robot.

According to the principle of compatibility, substantial correlations between attitudinal and behavioural measures will only be found if these constructs are assessed at the same level of generality in terms of act, target, context and time [28], and therefore it is assumed:

H3 Positive context-related attitudes towards the usefulness of care robots explain the care personnel's behavioural intentions related to the introduction of care robots better than the NARS.

\section{Material and methods}

Sample

The research data were collected in five municipalities in different parts of Finland from March to May 2016. A total of 200 Finnish home care workers answered the questionnaire. The share of women 
was $94 \%$, and the average age of the respondents was 43 years. The duration of work experience in home care varied from a few months to 39 years. Half of the respondents $(52 \%)$ had worked in home care for at least ten years, and 20\% for at least 20 years. (Cf. Table 2.)

Table 2: Respondents.

\begin{tabular}{llcc}
\hline Background variable & Value & Sample & Corresponding national value \\
\hline Age (average) & & 43 years & 43 years ${ }^{1)}$ \\
\hline & Women & $94 \%$ & $94 \%^{1)}$ \\
& Men & $6 \%$ & $6 \%^{1)}$ \\
\hline & Finnish & $96 \%$ & $89 \%^{2)}$ \\
& Swedish & $4 \%$ & $5 \%^{2)}$ \\
\hline & Practical nurses & $60 \%$ & $70 \%^{3)}$ \\
& Nurses & $22 \%$ & $12 \%^{3)}$ \\
& Other & $18 \%$ & $28 \%^{3)}$ \\
\hline West Finland & $42 \%$ & $30 \%^{5)}$ \\
& Helsinki-Uusimaa & $18 \%$ & $21 \%^{5)}$ \\
& South Finland & $18 \%$ & $24 \%^{5)}$ \\
& North \& East Finland & $22 \%$ & $1 \%^{5)}$ \\
\hline
\end{tabular}

1 In Super, which is a large labour union in the health care sector in Finland [29]

2 Mother tongue in the Finnish population [30]

3 In home care personnel in Finland [31]

4 NUTS 2 (Nomenclature of Territorial Units for Statistics) [32]

5 Population [30]

\section{Methods}

The questionnaire contained a total of 26 Likert-type scale items (ranging from $1=$ totally disagree to $5=$ totally agree) regarding the attitudes towards robots and five Likert-type scale items related to behavioural intention. The original language of the questionnaire was Finnish, and a Finnish translation from the English-language version of NARS [12] was used. The questionnaire was also translated into Swedish by an official translator. For this article, items have been translated into English by an official translator. The validation of measures was based, at first, on face validation by focus group interviews in Finnish home care ( 8 groups, total of 40 participants) and pre-testing among nursing students $(n=15)$. Sub-scales were formed by using exploratory factor analysis (Principal Axis Factoring method, Varimax rotation with Kaiser Normalization), while the internal consistency of scales was estimated with Cronbach's alpha.

The data were analysed using IBM SPSS Statistics for Windows, version 23 (IBM corp., Armonk, N.Y., USA). The normality of distributions was checked using histograms, and this analysis showed that the distributions of the sum variables were close to normal. In principle, a Likert scale is ordinal but a number of researchers [33] have suggested that parametric methods can be utilized in the case 
of sum variables based on Likert-type scale items as well. According to Clason and Dormody, there are no hard and fast rules for sufficiently determining how normal is normal in the case of Likert scales, hence it is necessary to make the decisions using different criteria [34]. Thus, the dependencies were examined parametrically.

The actual statistical analyses were conducted using the Pearson product-moment correlation coefficient and linear regression analysis with the Enter method. Before carrying out regression analyses, the validity of the conditions were checked. The normality of the residuals' distributions and the linearity condition were checked graphically, while multicollinearity between the independent variables was tested using VIF coefficients. The assessment of effect size of Pearson correlation coefficients is based on Cohen's study, whereby the limits of small, medium and large effects are .1, .3 and .5 respectively [35]. Overall, the missing values were very minimal (no more than two per item). Preliminary analyses were done using the original data, but the missing values were replaced by a value of 3 (= neither agree nor disagree) when forming the sum variables.

\section{Measures}

Negative attitudes are examined using Nomura's Negative Attitudes towards Robots Scale (NARS) [12], which consists of three sub-scales and a total of 14 questions. The sub-scales are associated with the human-robot interaction in specific situations, the social influences of robots, and the humanrobot interaction and emotions related to it. Alongside the NARS, Nomura later developed the Robot Anxiety Scale [14] and the Rapport-expectation with a Robot Scale [36] and, together with the Syrdal et al. [22], they have analysed positive attitudes towards robots, although these scales are not used in this study.

Positive attitudes were examined from the perspective of the perceived usefulness of care robots for different tasks in home health care and the promotion of the independent living of older people. Based on previous studies $[15,17,19,37]$, twelve questions were prepared related to the use of robots in the promotion of safety, medication, advanced telecommunication, practical health care, household work, guiding, reminding older people, lifting and moving older people, as well as easing the anxiety and loneliness of older people.

As per Armitage and Conner's meta-analyses, the behavioural intentions were examined using a number of different measures that focus not only on the actual intention, but also on desires and selfpredictions [38]. Alaiad and Zhou have constructed a measure of the usage intention of health care 
robots, but there are no valid measures relating to the introduction of care robots in the context of home care [15]. In this study, the measure for behavioural intention contained five questions related to a person's specific readiness, enthusiasm or motivation to introduce and use care robots. One question concerned the introduction of technological applications in general ('Generally, I'm ready to and even enthusiastic about implementing new technological applications if they can enhance the quality of work of home care'). Other questions related to the introduction of care robots for the promotion of coping at home (' $I$ would be ready for experimenting and introducing new robotic technology in home care if it could ease older people's independent coping at home'), safety ('I would be ready for the introduction of care robots that ensure the safety of older people who live at home'), safety of medication ('I would be enthusiastic about introducing robotic technology that enhances the safety of medication in home care') and everyday tasks in home care ('I would be very motivated to introducing robotic technology that eases everyday tasks in home care and to the instruction of customers it requires').

In this study, age is examined as a control variable, since previous studies [9, 10, 39, 40] have shown that it is a relevant factor in attitudes towards robots.

\section{Ethical issues}

The research approvals were acquired according to the policies of each organization and an information letter included a summary of the research plan. The participants were informed about the voluntary nature of their contribution. The information letter explained the confidentiality of the responses and that they would remain anonymous. Information on how to contact researchers was attached to the information letter so that the participants could communicate with them if they had any questions or comments regarding the study. Anonymity was guaranteed as the replies were returned without any personnel data. Data were then handled with absolute confidentiality and the results are published in a way that prevents the identification of individual participants. The results of the study have been presented in an objective, open and honest manner. [41, 42]. 


\section{Results}

\section{Validation of attitudes towards robots scales}

Before the preparation of the questionnaire, eight focus group interviews were held in Finnish municipal home care facilities. The aim of these employee interviews $(n=40)$ was to form a conceptualization of home care work and its challenges. The developed questionnaire was pre-tested among nursing students $(n=15)$ by using the form that included questions regarding structure and design of the questionnaire, ease of answering, comprehensibility of the statements, and clarity of the response alternatives provided. Only some minor changes related to the layout and wording were made after the pre-testing.

Sum variables related to the NARS were formed using exploratory factor analysis. The three factor model explains about $58 \%$ of the total variation of the variables (see Table 3 ). The sum variable of the NARS 1 (sub-scale 1 of the NARS) was formed of the four questions that loaded most highly on factor 3, the NARS 2 (sub-scale 2) was constructed based on factor 2 (4 issues) and the NARS 3 (subscale 3 ) based on factor 1 (4 issues). In previous studies, the questions in the NARS are loaded in slightly contradictory ways, and in this study, the factor analysis was partly in line with Nomura's original scale and partly with Syrdal's et al. study [20]. This study, the question of 'I would feel paranoid talking with a robot' loaded in contrast to Nomura's et al. study into sub-scale 2, which was associated with the social influences of robots. However, since the content of the statement does not relate to the social influences of robots, it was excluded from the final measure in the present study. Consistent with Syrdal et al. [20] and in contrast to Nomura et al. [12], the issue of ' $I$ would feel uneasy if robots really had emotions' loaded in sub-scale 3 and the issue of 'The word 'robot' means nothing to me' loaded onto no factor. 
Table 3: Factor analysis: Negative attitudes towards robots.

\begin{tabular}{|c|c|c|c|c|c|}
\hline \multirow[b]{2}{*}{ Item } & \multicolumn{2}{|c|}{ Previous studies } & \multicolumn{3}{|c|}{ This study } \\
\hline & $\begin{array}{l}\text { Sub-scale (ori- } \\
\text { ginal NARS by } \\
\text { Nomura et al.) }\end{array}$ & $\begin{array}{l}\text { Factor } \\
\text { (sub-scale) } \\
\text { (Syrdal) }\end{array}$ & $\begin{array}{c}\text { Factor } 1 \\
\text { (S3) }\end{array}$ & $\begin{array}{l}\text { Factor } 2 \\
\text { (S2) }\end{array}$ & $\begin{array}{c}\text { Factor } 3 \\
\text { (S1) }\end{array}$ \\
\hline $\begin{array}{l}1 \text { I would feel uneasy if robots really had } \\
\text { emotions. }\end{array}$ & $\mathrm{S} 2$ & F2 (S3) & .541 & & \\
\hline $\begin{array}{l}2 \text { Something bad might happen if robots } \\
\text { developed into living beings. }\end{array}$ & $\mathrm{S} 2$ & $\begin{array}{l}\text { F1 (S2) / } \\
\text { F3 (S1) }\end{array}$ & & .389 & \\
\hline 3 I would feel relaxed talking with robots ${ }^{1)}$ & S3 & F2 (S3) & -.439 & & \\
\hline $\begin{array}{l}4 \text { I would feel uneasy if I was given a job } \\
\text { where I had to use robots. }\end{array}$ & S1 & F3 (S1) & & & .583 \\
\hline $\begin{array}{l}5 \text { If robots had emotions I would be able to } \\
\text { make friends with them. }{ }^{1)}\end{array}$ & S3 & F2 (S3) & -.823 & & \\
\hline $\begin{array}{l}6 \text { I feel comforted being with robots that } \\
\text { have emotions. }{ }^{1)}\end{array}$ & S3 & F2 (S3) & -.887 & & \\
\hline $\begin{array}{l}7 \text { The word 'robot' means nothing to } \\
\text { me. }\end{array}$ & S1 & & & & \\
\hline $\begin{array}{l}8 \text { I would feel nervous operating a robot in } \\
\text { front of other people. }\end{array}$ & S1 & & & & .770 \\
\hline $\begin{array}{l}\text { 9 I would hate the idea that robots or } \\
\text { artificial intelligences were making } \\
\text { judgements about things. }\end{array}$ & S1 & F1 (S2) & & & .540 \\
\hline $\begin{array}{l}10 \text { I would feel very nervous just standing } \\
\text { in front of a robot. }\end{array}$ & S1 & F3 (S1) & & & .647 \\
\hline $\begin{array}{l}11 \text { I feel that if I depend on robots too } \\
\text { much, something bad might happen. }\end{array}$ & $\mathrm{S} 2$ & F1 (S2) & & .495 & \\
\hline $\begin{array}{l}12 \text { I would feel paranoid talking with a } \\
\text { robot. }^{2)}\end{array}$ & S1 & F2 (S3) & & .586 & \\
\hline $\begin{array}{l}13 \text { I am concerned that robots would be a } \\
\text { bad influence on children. }\end{array}$ & & F1 (S2) & & .722 & \\
\hline $\begin{array}{l}14 \text { I feel that in the future society will be } \\
\text { dominated by robots. }\end{array}$ & S2 & & & .700 & \\
\hline
\end{tabular}

Issues of positive attitudes were loaded towards three factors (cf. Table 4). The first factor, robots as promoters of safety refers to the belief that it is possible to promote the safety of older people using care robots, and it consists of four statements relating in particular to medication, health monitoring, and communication with relatives and healthcare personnel. Issues relating to the second factor (robots as helpers in practical home care) focused on the use of robots in housework, assisting in the moving and washing of older people etc. Onto the third factor (robots as guides and prompters) three questions were loaded to the guidance of older people in physical exercises, using the phone or bank matters, as well as providing reminders. One of the statements ('A care robot can ease the anxiety 
and loneliness of an older person') was not loaded towards any of the factors, and it was excluded from the sum variables.

Table 4: Positive attitudes towards care robots.

\begin{tabular}{|c|c|c|c|c|}
\hline $\begin{array}{l}\text { Items } \\
\text { A care robot can... }\end{array}$ & $\mathrm{N}$ & $\begin{array}{c}\text { Factor } \\
1\end{array}$ & $\begin{array}{l}\text { Factor } \\
2\end{array}$ & $\begin{array}{l}\text { Factor } \\
3\end{array}$ \\
\hline help an older person with washing, dressing up and using the toilet & 200 & & .639 & \\
\hline help an older person move (e.g. moving from bed to chair) & 200 & & .713 & \\
\hline remind an older person to take their medicine, of week days, of meetings & 200 & & & .538 \\
\hline guide an older person with the use of phone or bank-related issues & 199 & & & .516 \\
\hline $\begin{array}{l}\text { assist an older person in light household work (e.g. cooking, making } \\
\text { their bed, doing the dishes, using the dishwasher) }\end{array}$ & 199 & & 675 & \\
\hline $\begin{array}{l}\text { assist an older person in heavy household work (cleaning the windows, } \\
\text { lifting) }\end{array}$ & 200 & & .685 & \\
\hline ease the anxiety and loneliness of an older person & 198 & & & \\
\hline help an older person communicate with relatives and friends & 199 & .597 & & \\
\hline guide an older person in physical exercise & 200 & & & .684 \\
\hline $\begin{array}{l}\text { help observing an older person's state of health (i.e. remote communi- } \\
\text { cation with doctor or nurse, real-time conveying of health information) }\end{array}$ & 200 & .752 & & \\
\hline $\begin{array}{l}\text { help with medication (e.g. giving medicine, recognising medicine, } \\
\text { observing medicine use) }\end{array}$ & 200 & .666 & & \\
\hline $\begin{array}{l}\text { contribute to the safety of an older person living at home (e.g. by infor- } \\
\text { ming relatives and/or health care workers of sudden change in the state } \\
\text { of health) }\end{array}$ & 200 & .760 & & \\
\hline
\end{tabular}

The reliabilities of positive attitudes and behavioural intention were quite high $(\alpha>8)$, and in turn, the reliabilities of sum variables related to the NARS were not quite as good, though only one alpha coefficient was well below .8. (Cf. Table 5.)

Table 5: Sum variables and their reliabilities.

\begin{tabular}{|c|c|c|c|c|c|}
\hline Variable & $\mathbf{N}$ & mean & SD & Items & Alpha \\
\hline Behavioural intention & 199 & 3.56 & 0.91 & 5 & .875 \\
\hline NARS 1 & 200 & 2.79 & 0.93 & 4 & .799 \\
\hline NARS 2 & 200 & 3.06 & 0.90 & 4 & .730 \\
\hline NARS 3 & 200 & 3.92 & 0.91 & 4 & .795 \\
\hline Robots as promoters of safety & 199 & 3.38 & 1.09 & 4 & .865 \\
\hline Robots as helpers in practical home care & 199 & 2.58 & 1.05 & 4 & .824 \\
\hline Robots as guides and prompters & 199 & 3.78 & 0.97 & 3 & .817 \\
\hline
\end{tabular}


Table 6 shows that a person's intention to introduce care robots depends strongly on that person's positive attitudes towards care robots. All of the correlation coefficients were more than .5 , that is to say the effect size is large, with the exception of the correlation between behavioural intention and attitudes related to robots as helpers in practical home care. Also, the effect size of the correlation between the NARS 1 and behavioural intention is large. The other two sub-scales of the NARS correlated with the behavioural intention at the medium level $(.3<r<.5)$ (cf. Table 6). Furthermore, it should be noted that different attitudes correlate strongly with each other.

Table 6: Correlation between variables (Pearson).

\begin{tabular}{|c|c|c|c|c|c|c|c|}
\hline Variable & $\begin{array}{l}\text { Behavioural } \\
\text { intention }\end{array}$ & NARS1 & NARS2 & NARS3 & $\begin{array}{l}\text { Robots as } \\
\text { promoters } \\
\text { of safety }\end{array}$ & $\begin{array}{l}\text { Robots as } \\
\text { helpers in } \\
\text { practical } \\
\text { home care }\end{array}$ & $\begin{array}{l}\text { Robots as } \\
\text { guides } \\
\text { and } \\
\text { prompters }\end{array}$ \\
\hline Behavioural intention & 1 & & & & & & \\
\hline NARS 1 & $-.508 * * *$ & 1 & & & & & \\
\hline NARS 2 & $-.441 * * *$ & $.549 * * *$ & 1 & & & & \\
\hline NARS 3 & $-.386 * * *$ & $.484 * * *$ & $.471 * * *$ & 1 & & & \\
\hline R. as promoters of safety & $.648 * * *$ &,$- 453 * * *$ &,$- 335 * * *$ & $-.319 * * *$ & 1 & & \\
\hline R. as helpers in practical ... & $.484 * * *$ &,$- 324 * * *$ &,$- 290 * * *$ &,$- 370 * * *$ & $.531 * * *$ & 1 & \\
\hline R. as guides and prompters & $.619 * * *$ &,$- 355 * * *$ &,$- 349 * * *$ &,$- 245 * * *$ & $.671 * * *$ & $.617 * * *$ & 1 \\
\hline Age & -.064 &,- 013 &,- 038 &,$- 159^{*}$ & -.093 & -.061 & -.080 \\
\hline
\end{tabular}

Regression models explaining psychological readiness to introduce care robots in home care

A linear regression analysis was employed to examine the factors that explain behavioural intention. The first model in Table 7 relates to the dependence between negative attitudes and behavioural intentions and the second model to the dependence between positive attitudes and behavioural intentions. The third model combines negative and positive attitudes. Model A includes all independent variables that are examined, and model B is a final model from which the non-significant variables $(p>.05)$ have been removed one by one.

The results are consistent with hypotheses 1 and 2 . According to model 1 , there are significant $(p<.01)$ dependencies between negative attitudes towards robots and behavioural intentions, and according to model 2, dependencies between some positive attitudes and behavioural intentions are also significant. The most relevant variable related to attitudes towards robots seems to be a belief that in using care robots, it is possible to promote the safety of older people. In addition, a belief that robots 
can be used in guiding physical activities and reminding older people would seem to be positively associated with psychological readiness to introduce care robots. All of these significant dependencies remain also in the 3 models.

Table 7: Regression analyses. Dependent variable: behavioural intention (stand. beta)

\begin{tabular}{|c|c|c|c|c|c|c|}
\hline \multirow[b]{2}{*}{ Independent variable } & \multicolumn{2}{|c|}{$\begin{array}{l}\text { NARS models } \\
\quad(\mathrm{H} 1)\end{array}$} & \multicolumn{2}{|c|}{$\begin{array}{c}\text { Specific positive } \\
\text { attitudes models (H2) }\end{array}$} & \multicolumn{2}{|c|}{$\begin{array}{c}\text { Combination models } \\
\text { (H1, H2 and H3) }\end{array}$} \\
\hline & $\begin{array}{l}\text { Model } \\
1 \mathrm{~A}\end{array}$ & $\begin{array}{l}\text { Model } \\
\text { 1B }\end{array}$ & $\begin{array}{l}\text { Model } \\
2 \mathrm{~A}\end{array}$ & $\begin{array}{l}\text { Model } \\
\text { 2B }\end{array}$ & $\begin{array}{l}\text { Model } \\
\text { 3A }\end{array}$ & $\begin{array}{l}\text { Model } \\
\text { 3B }\end{array}$ \\
\hline NARS 1 & $-.332 * * *$ & $-.381 * * *$ & - & - & $-.165^{*}$ & $-.188 * *$ \\
\hline NARS 2 & $-.192 * *$ & $-.231 * *$ & - & - & -.105 & $-.127 *$ \\
\hline NARS 3 & $-.150 *$ & - & - & - & -.083 & - \\
\hline Robots as promoters of safety & - & - & $.405^{* * *}$ & $.424 * * *$ & $.306 * * *$ & $.328 * * *$ \\
\hline Robots as helper in practical home care & - & - & .090 & - & .040 & - \\
\hline Robots as guides and prompters & - & - & $.291 * * *$ & $.334 * * *$ & $.271 * * *$ & $.288 * * *$ \\
\hline Age & -.099 & - & .003 & - & -.031 & - \\
\hline$F$ & $22.4 * * *$ & $41.4 * * *$ & $45.6^{* * *}$ & $91.5^{* * *}$ & $33.1 * * *$ & $57.7 * * *$ \\
\hline$R^{2} /$ Adjusted $R^{2}$ & $.317 / .303$ & $.296 / .289$ & $.486 / .475$ & $.482 / .476$ & $.550 / .533$ & $.542 / .533$ \\
\hline
\end{tabular}

\section{Discussion}

\section{Main findings and general discussion}

The study shows that the Negative Attitudes towards Robot Scale [8] helps explain psychological resistance related to the introduction of care robots, i.e. the negative attitudes towards robots affects how willing home care workers are to introduce care robots into their work. However, according to the study, the NARS may be susceptible to cultural differences, such as was shown by Syrdal et al. [20]. In the Finnish sample, the items of the NARS have not loaded onto factors in accordance with Nomura's original scale and nor are they consistent with Syrdal et al. [20]. In addition, the reliabilities of the sum variables of the NARS was only at the moderate level (the alphas were between .73-.80).

The results show that attitudes are an important factor in the adoption of robots. However, the examination of attitudes is necessary to combine two different approaches. Previous studies have 
shown that negative attitudes towards robots affect behaviour in human-robot interaction [13, 14], and this study shows that they also have a significant effect on behavioural intentions related to the introduction of care robot. As in previous studies $[15,16,17,18,19]$ it was also important to study the perceived usefulness of care robot for different tasks in home health care and in promoting of independent living of older people.

According to the regression analyses, specific positive attitudes related to perceived usefulness of care robots for different practical task can explain behavioural intentions more strongly than the negative attitudes that do not relate to the context of home care or the supporting of older people. However, comparison of the effect sizes of correlation coefficients did not highlight any clear differences between the effects of negative and positive attitudes (cf. Table 8). Thus, hypothesis 3, which is based Fisbein and Ajzen's argument that specific attitudes explain and predict behaviour in specific situations much better than general attitudes [25], did not receive unambiguous support, although the results are in line with the hypothesis.

Table 8: Comparison of two types of attitudes. Effect sizes of Person's correlation coefficient between the variable and behavioural intention.

\begin{tabular}{|c|c|c|c|c|}
\hline Type of attitudes & $\begin{array}{l}\text { Explained of } \\
\text { the variance in } \\
\text { behavioural } \\
\text { intention }\end{array}$ & Variable & Perspective & $\begin{array}{l}\text { Effect size } \\
\text { of } \\
\text { correlation }\end{array}$ \\
\hline & & $\begin{array}{l}\text { NARS } 1 \text { (human-robot } \\
\text { interaction) }\end{array}$ & Psychological reactions & large effect \\
\hline & & $\begin{array}{l}\text { NARS } 2 \text { (social } \\
\text { influence of robots) }\end{array}$ & Societal attitudes & $\begin{array}{l}\text { medium } \\
\text { effect }\end{array}$ \\
\hline & & $\begin{array}{l}\text { NARS } 3 \text { (emotions in } \\
\text { human robot-interaction) }\end{array}$ & Psychological reactions & $\begin{array}{l}\text { medium } \\
\text { effect }\end{array}$ \\
\hline & & $\begin{array}{l}\text { Robots as promoters of } \\
\text { safety }\end{array}$ & $\begin{array}{l}\text { Practical care and the promotion } \\
\text { of independent living }\end{array}$ & large effect \\
\hline & & $\begin{array}{l}\text { Robots as helper in } \\
\text { practical home care }\end{array}$ & $\begin{array}{l}\text { Practical care and the promotion } \\
\text { of independent living }\end{array}$ & $\begin{array}{l}\text { medium } \\
\text { effect }\end{array}$ \\
\hline & & $\begin{array}{l}\text { Robots as guides and } \\
\text { prompters }\end{array}$ & $\begin{array}{l}\text { Practical care and the promotion } \\
\text { of independent living }\end{array}$ & large effect \\
\hline
\end{tabular}

1 Model A in regression analysis (all independent variables)

2 Model B in regression analysis (only significant independent variables)

According to the principle of compatibility, substantial correlations between attitudinal and behavioural measures will only be found if these constructs are assessed at the same level of generality [28]. The NARS 1 is associated with robots in general, and specifically to a human-robot interaction, 
while the measure of behavioural intentions is targeted at the introduction of care robots and related to the context of home care, and so, they are not at the same level, and the high correlation between them was not fully expected. One explanation for the result may relate to the fact that robots are still quite unknown to many respondents. Although issues contained in the measure of behavioural intentions are, in principle, on a concrete level, they may be understood more abstractly among home care personnel and thus also affect general fears related to the human-robot interaction on behavioural intentions.

Nomura's scale is a combination of different elements, including questions concerning the humanrobot interaction and emotions related to it, as well as questions about the social influence of robots. According to the findings, the importance of attitudes towards the interaction with robots (first subscale) is the largest. According to the regression models, the effect of attitudes towards the social influence of robots is significant. The study shows that the examination of attitudes toward robots is not justified in focusing only on one aspect, but a better explanation is achieved by combining the perspectives of societal attitudes, attitudes related to psychological reactions, and the practical care and the promotion of the independent living of older people.

According to the World Health Organization, there will be global health workforce shortage reaching 12.9 million in coming decades, and this means we need to find new solutions for home care [43]. Care robots can form a part of this solution. According to a literature review by Agnihotri and Gaur, the majority of earlier studies support the hypothesis of the effectiveness of socially assistive robots, and using robots to assist in daily activities in geriatric health care [2]. However, a lot of development and research is required to enable the robots to meet the challenges related to an aging of the population and the increased need for care (for example drug administration, loneliness, nutrition).

\section{Methodological strengths and limitations}

The research data were collected in five municipalities in different parts of Finland. The sample was formed to be regionally comprehensive, and the representativeness of the survey turned out to be quite good. However, in some respects the material is not fully representative. For example, the Helsinki-Uusimaa region is home to about $30 \%$ of the Finnish population (cf. Table 2), but in the data the share of this area is only $18 \%$. In addition, the share of practical nurses in the research data is lower than average in Finnish home care. In contrast, respondents of western Finland and nurses are 
over-represented in the data. The share of women was close to the corresponding national proportion for care personnel, and the average age of the respondents was close to the national average.

The response percentage in the data as a whole is about $18 \%$. In two municipalities $(n=114$; response rate $58 \%$ ) data were collected in paper form during the staff development days and all participants present answered the questionnaire, although some employees did not participate in the development days due to vacations, sick leave, and the necessary tasks of home care. In other municipalities ( $n=86$; response rate $9 \%$ ) an electronic questionnaire was used. These two groups did not differ significantly from each other in respect to behavioural intention $(t=.805, p=.422)$.

\section{Conclusions}

In terms of the introduction of care robots into home care, personnel attitudes and perceptions towards robots play a key role. This underlines the importance of comprehensive training, which includes not only teaching technological skills, but promoting positive attitudes and a positive working atmosphere. As part of this process, it is necessary to discuss the various fears related to robots. Also, more research is needed on the different types of robot applications in home care.

There are some ethical themes that should also be considered, for example the older person's right to decide whether to accept or refuse care robot help. Adopting care robot technology presents some challenges. Firstly, implementing care robots in home care impacts upon the self-determination belonging to every older person. Nobody should be forced to use robots, but services should be developed to reflect the wishes of older people. Secondly, the different fears and worries associated with the use of care robots should be taken into consideration. Providing older persons and home care personnel with information about different robots may help reduce these fears, and aid in the acceptance and adoption of this form of technology. However, the responsibility for this should be shared between manufacturers, service providers and users.

When looking at the future implementation of care robots, analysis has to extend beyond general attitudes. It is essential to use specific and context-related measures that relate to concrete care issues and the everyday life of clients. Previous research has also shown that it is necessary to pay special attention to the cultural validity of these measures, especially when attitude scales are applied to countries other than their original setting. 


\section{References}

1 Bouwhuis DG. Current use and possibilities of robots in care. Gerontechnology 2016; 15 (4): 198-208. DOI: http://dx.doi.org/10.4017/gt.2016.15.4.003.00.

2 Agnihotri R, Gaur S. Robotics: A new paradigm in geriatric healthcare. Gerontechnology 2016; 15 (3): 146-161.

3 Home care. 2015. https://www.he 1.fi/helsinki/en/socia-health/elderly/home/ (accessed 2.6.2017)

4 Chau PYK, Hu PJ-H. Information technology acceptance by individual professionals: A model comparison approach. Decision Sci 2001; 32 (4): 699-719.

5 Holden RJ, Karsh B-T. The Technology Acceptance Model: Its past and its future in health care. J Biomed Inform 2010; 43: 159-172.

6 Rawstorne P, Jayasuriya R, Caputi P. Issues in Predicting and Explaining Usage Behaviors with the Technology Acceptance Model and the Theory of Planned Behavior When Usage Is Mandatory. International Conference on Information Systems (ICIS), AIS Electronic Library (AISeL). 2000.

7 Eagly AH, Chaiken S. The Psychology of Attitudes. Fort Worth, TX: Harcourt Brace Jovanovich, 1993.

8 European Commission. Public Attitudes towards Robots. Special Eurobarometer 382, 2012. http://ec.europa.eu/public_opinion/archives/ebs/ebs 382 en.pdf.

9 Kuo H, Rabindran JM, Broadbent E, Lee YI, Kerse N, Stafford RMQ, MacDonald BA. Age and gender factors in user acceptance of healthcare robots. The 18th IEEE International Symposium on Robot and Human Interactive Communication. Toyama, Japan, Sept. 27-Oct. 2, 2009.

10 Scopelliti M, Giuliani MV, Fornara F. Robots in a domestic setting: A psychological approach. Universal Access in the Information Society 2005; 4: 146-155.

11 Wu Y-H, Cristancho-Lacroix V, Fassert C, Faucounau V, de Rotrou J, Rigaud A-S. The Attitudes and Perceptions of Older Adults With Mild Cognitive Impairment Toward an Assistive Robot. J Appl Gerontol 2016; 35 (1): 3-17.

12 Nomura T, Kanda T, Suzuki T. Experimental Investigation into Influence of Negative Attitudes Toward Robots on Human-Robot Interaction. AI Soc 2006; 20: 138-150.

13 Nomura T, Suzuki T, Kanda T, Kato K. Altered attitudes of people toward robots: Investigation through the negative attitudes toward robots scale. Proceeding of the AAAI-06 Workshop on Human Implications of Human-Robot Interaction, Boston, USA. 2006: 29-35.

14 Nomura T, Kanda T, Suzuki T, Kato K. Prediction of Human Behavior in Human-Robot Interaction Using Psychological Scales for Anxiety and Negative Attitudes Toward Robots. IEEE transactions on robotics 2008; 24 (2).

15 Alaiad A, Zhou L. The determinants of home healthcare robots adoption: An empirical investigation. Int J Med Inform 2014; 83: 825-840. 
16 Beedholm K, Frederiksen K, Skovsgaard Frederiksen A-M, Lomborg K. Attitudes to a robot bathtub in Danish elder care: A hermeneutic interview study. Nurs Health Sci 2015, 17, 280286.

17 Broadbent E, Tamagawa R, Patience A, Knock B, Kerse N, Day K, MacDonald B. Attitudes towards health-care robots in a retirement village. Australas J Ageing 2012; 31 (2): 115-120.

18 Fischinger D, Einramhof P, Papoutsakis K, Wohlkingera W, Mayerc P, Panekc P, Hofmanne S, Koertner T, Weissa A, Argyros A, Vincze M. Hobbit, a care robot supporting independent living at home: First prototype and lessons learned. Robot Auton Syst; 2016; 75: 60-78.

19 Mast M, Burmester M, Kruger K, Fatikow S, Arbeiter G, Graf B, Kronreif G, Pigini L, Facal D, Qiu R. User-centered design of a dynamic-autonomy remote interaction concept for manipulation-capable robots to assist elderly people in the home. Journal of Human-Robot Interaction 2012; 1 (1): 96-118. DOI: 10.5898/JHRI.1.1.Mast.

20 Syrdal DS, Dautenhahn K, Koay KL, Walters ML. The Negative Attitudes towards Robots Scale and Reactions to Robot Behaviour in a Live Human-Robot Interaction Study. Adaptive and Emergent Behaviour and Complex Systems: Procs of the 23rd Convention of the Society for the Study of Artificial Intelligence and Simulation of Behaviour, AISB 2009: 109-115.

21 MacDorman, KF, Vasudevan SK\& Ho C-C. Does Japan really have robot mania? Comparing attitudes by implicit and explicit measures. AI \& Soc 2009; 23 (4): 485-510. DOI: 10.1007/s00146-008-0181-2.

22 Syrdal DS, Nomura T, Dautenhahn K. The Frankenstein Syndrome Questionnaire - Results from a Quantitative Cross-cultural Survey. Social Robotics, 5th International Conference, ICSR, Bristol, UK, October 27-29, 2013.

23 Ajzen I. The theory of planned behavior. Organizational Behavior and Human Decision Process 1991; 50: 179-211.

24 Ajzen I. Nature and Operation of Attitudes. Annu Rev Psychol 2001; 52: 27-58.

25 Ajzen I, Fishbein M. Attitudes and the Attitude-Behavior Relation: Reasoned and Automatic Processes. Eur Rev Social Psychol 2000; 11 (1): 1-33.

26 Ministry of Social Affairs and Health. 2017. http://stm.fi/kotihoito-kotipalvelut (accessed 4.1.2016).

27 Turjamaa R, Hartikainen S, Kangasniemi M, Pietilä A-M. Is it time for a comprehensive approach in older care clients care planning in Finland? Scand J Caring Sci 2015; 29: 317324.

28 Ajzen I, Fishbein M. The Influence of Attitudes on Behavior. In Albarracín D, Johnson BT, Zanna, MP (eds.), The Handbook of Attitudes. Mahwah, NJ: Erlbaum 2005: 173-221.

29 Super. The Finnish union of practical nurses. https://www.superliitto.fi/viestinta/tilastot/ (accessed 13.3.2017).

30 Official Statistics of Finland (OSF): Annual national accounts. Helsinki: Statistics Finland. http://www.tilastokeskus.fi/tup/suoluk/suoluk_vaesto.html (accessed 13.3.2017). 
31 Skill mix. The National Institute for Health and Welfare (THL). http://www.thl.fi/attachments/vanhuspalvelulainseuranta/kotihoito/2014/Henkilostorakenne. html (accessed 13.3.2017).

32 Nomenclature of Territorial Units for Statistics. European Union. http://ec.europa.eu/eurostat/web/nuts/local-administrative-units (accessed 13.3.2017).

33 Norman G. Likert scales, levels of measurement and the "laws" of statistics. Advance in Health Science Education 2010; 15 (5): 625-632.

34 Clason DL, Dormody TJ. Analyzing Data Measured by Individual Likert-Type Items. J Agr Educ 1994; 35 (4): 31-35.

35 Cohen JA. Power Primer. Psychol Bull 1992; 112 (1): 155-159.

36 Nomura T, Kanda T. Who Expect Rapport with Robots? A Survey-Based Study for Analysis of People's Expectation. Technical Report, 2015. DOI: 10.13140/RG.2.1.3452.5602.

37 Bedaf S, Gelderblom GJ, Syrdal DS, Lehman H, Michel H, Hewson D, Amirabdollahian F, Dautenhahn K, deWitte L. Which activities threaten independent living of elderly when becoming problematic: inspiration for meaningful service robot functionality. Disabil Rehabil Assist Technol 2013. DOI: 10.3109/17483107.2013.840861.

38 Armitage CJ, Conner M. Efficacy of the Theory of Planned Behaviour: A meta-analytic review. Brit J Social Psychol 2001; 40: 471-499.

39 Bartneck C, Nomura T, Kanda T, Suzuki T, Kennsuke K. A cross-cultural study on attitudes towards robots. Proceedings of the HCI International, Las Vegas, 2005.

40 Ezer N, Fisk AD, Rogers WA. Attitudinal and Intentional Acceptance of Domestic Robots by Younger and Older Adults. Universal Access in Human-Computer Interaction 2009; 5615: 39-48. DOI: 10.1007/978-3-642-02710-9 5.

41 The Finnish Advisory Board on Research Integrity. Responsible conduct of research and procedures for handling allegations of misconduct in Finland. Guidelines of the Finnish Advisory Board on Research Integrity 2012. Retrieved 25.10.2015. http://www.tenk.fi/sites/tenk.fi/files/HTK_ohje_2012.pdf

42 WMA Declaration of Helsinki - Ethical Principles for Medical Research Involving Human Subjects. 2017 http://www.wma.net/en/30publications/10policies/b3/ (accessed 9.1.2017).

43 WHO. 2013. http://www.who.int/mediacentre/news/releases/2013/health-workforceshortage/en/(accessed 2.6.2017). 